\title{
Top oil heat distribution pattern of ONAN corn oil based transformer with presence of hot spot study using FEMM
}

\author{
M. A. Husin ${ }^{1}$, N. A. Othman ${ }^{2}$, N. A. Muhammad ${ }^{3}$, H. Kamarden ${ }^{4}$, M. S. Kamarudin ${ }^{5}$ \\ ${ }^{1,2,5}$ Department of Electrical Power Engineering, Faculty of Electrical \& Electronic Engineering, Universiti Tun Hussein \\ Onn Malaysia (UTHM), 86400 Batu Pahat, Malaysia \\ ${ }^{3}$ School of Electrical \& Electronics Engineering, Engineering Campus, Universiti Sains Malaysia (USM), \\ 14300 Nibong Tebal, Pulau Pinang, Malaysia \\ ${ }^{4}$ School of Electrical Engineering, Faculty of Engineering, Universiti Teknologi Malaysia (UTM), \\ 81310 Johor Bahru, Johor, Malaysia
}

\begin{tabular}{ll}
\hline \hline Article Info & ABSTRACT \\
\cline { 2 - 3 } Article history: & $\begin{array}{l}\text { Transformer thermal modelling is a crucial aspect to be considered as this } \\
\text { may help the determination of heat capacity of transformer. This paper } \\
\text { present, simulation study on Oil Natural Air Natural (ONAN) transformer } \\
\text { Received Dec 28, } 2018 \\
\text { hevised Mar 9, 2019 } \\
\text { (HST). This paper aims to compare the effects of different HST value at } \\
\text { different locations inside the transformer unit as well as to evaluate the top } \\
\text { oil thermal behaviour of corn oil as cooling mechanism in a transformer. To }\end{array}$ \\
achieve aforementioned objectives, three HSTs were introduced to the 30 \\
Keywords:
\end{tabular}$\quad \begin{aligned} & \text { MVA transformer winding to find the total heat build-up in the top of the } \\
& \text { transformer tank. The outcome of thermal properties is examined using x-y } \\
& \text { temperature plot. From the results found that the location of HST affects } \\
& \text { overall transformer's temperature. HST at the top of the winding give a } \\
& \text { significant effect compared to when HST is at the bottom of the winding. It is } \\
& \text { Heat distribution } \\
& \text { Hot spot temperature } \\
& \text { Vegetable oil } \\
& \text { the transformer. The findings suggest that the temperature distribution study } \\
& \text { especially on transformer is important to monitor in-service transformer in a } \\
& \text { non-invasive manner. }\end{aligned}$

Copyright $\odot 2019$ Institute of Advanced Engineering and Science. All rights reserved.

\section{Corresponding Author:}

Nordiana Azlin binti Othman,

Department of Electrical Power Engineering,

Universiti Tun Hussein Onn Malaysia (UTHM),

86400 Batu Pahat, Johor, Malaysia.

Email: ndiana@uthm.edu.my

\section{INTRODUCTION}

Power transformers can be considered as an important part of the electrical power system. Thus, it is very essential for power transformers to be operated within the safe limit so that a safe and reliable power system operation can be obtained. It is well known that one problem in large rating transformer is heat dissipation [1-3]. The heat generated inside the transformer without being dissipated may eventually reduce the life of transformers. The insulating oil that circulates inside transformer may absorb the heat from the transformer interior through conduction process [3]. This heat is dissipated into the ambient through natural means or by cooling devices using proper coolant [4]. However, there are areas inside a transformer where the heat might not have dissipated properly. Thus, this condition may lead to the heat being accumulated which after some period of time such heat accumulation may result in high temperature and eventually may reduce the life of the transformer radically $[5,6]$.

Generally, there are many losses which can contribute to heat generation [4, 7]. If the heat is uneven and is not dissipated properly, it may reduce the lifetime and effectiveness of the transformer. Yet, right 
temperature determination in transformer winding is desired, and the locations of hot spot temperature (HST) in the transformer winding also need further studies. Previous studies on transformer overheating detection depends on the usage of empirical formula (IEEE and IEC standard formulations), experimental studies on actual transformer and the usage of suitable computer based simulation thermal models [8, 9]. Empirical formula was used to calculate maximum interior temperatures by assuming the heating process of oil and winding to the charging and discharging process of a capacitor. IEEE gives precise formula to calculate the value of HST while IEC standards stipulate a factor to be multiplied with the measured average temperature rise to determine the winding hottest spot rise [10]. Furthermore, experimental studies also have been carried out to measure the temperature of oil inside the transformer [11,12] and the reliability of oil dielectric over the years. But in these methods, the limitation is that the empirical formulae are derived based on certain assumptions to generalize a formula to suit to any transformer. But these generalizations make the formula specific only for a certain transformer [10]. This is because some of the transformer design, construction and loading conditions change the transformer thermal response in a non-linear way which lead to poorly track on the thermal response of transformer.

Mineral oil has been widely used in the transformer application [13, 14] as it can generate poisonous substances due to oxidative instability. The disposal and clearance after equipment failure and spillage is also a very difficult to exercise. The leakage of mineral oil transformer can post a serious threat to environment if leakage or spillage. Due to these above mentions negative point attached to the mineral oil, its use is highly questionable in many countries. The use of silicon oil has some better properties like, high flash point (low flammability) but they are very expensive and also non-biodegradable [15]. Vegetable oil on the other hand is environmentally friendly, biodegradable, renewable, cheap, highly available and safer alternative insulating and cooling medium for transformer [16]. The characteristics of commercially available vegetable oils vary with the product and typical representative values of the most vital characteristic for the use of vegetables oils as transformer oils.

Literatures of thermal models simulation on the actual transformer using suitable software [17-20] can give an accurate overview of heat distribution pattern across the transformer geometry. One of the suitable software that can be used to study this problem is Finite Elements Method Magnetics (FEMM) where the transformer is modelled based on actual measurement of a transformer. This software also allows the user to locate the HST and the heat produced by working transformer as well as their temperature rising in two-dimensional (2D). As for corn oil as transformer insulator, there not much study of how heat was distributed when HST happen. Therefore, this paper presents a simulation study on the temperature distribution with the presence of HST in Oil Natural Air Natural (ONAN) corn oil-based transformer to see how heat in this type of insulation oil distributed inside the transformer tank.

\section{RESEARCH METHOD}

ONAN type transformer was selected to be modelled to consider their thermal characteristics. The transformer cross-sectional diameter is based on the actual diameter of transformer, but the sizing is converted into millimetre. FEMM software is used to recreate the cross-sectional model of 3 phase ONAN type transformer in $2 \mathrm{D}$ as the chosen software allows us to find their thermal behaviour by showing the transformer heat flow. It is followed by the recorded data and analysis to determine whether their HST locations affect the total heat build-up in the transformer.

The details of the 30 MVA transformer parameters are tabulated in Table 1. The 30 MVA transformer is simulated with respect of the actual transformer nameplate rating. It is worth stating that the nameplate of the transformer is given by the Tenaga Nasional Berhad (TNB) and been simulated by using FEMM software.

Table 1. Nameplate rating of the 30 MVA transformer

\begin{tabular}{ccc}
\hline Parameter & Value & Unit \\
\hline Type of cooling & ONAN / ONAF & - \\
Voltage HV/LV (No Load) & $132 / 11$ & $\mathrm{KV}$ \\
Current HV/LV & $131.22 / 1574.9$ & $\mathrm{~A}$ \\
Phase & 3 & - \\
Frequency & 50 & $\mathrm{~Hz}$ \\
Connection symbol & YNdII & - \\
Year of manufacture & 1997 & - \\
Core and winding & 44400 & $\mathrm{Kg}$ \\
Oil mass & 21670 & $\mathrm{Kg}$ \\
Total mass & 88000 & $\mathrm{Kg}$ \\
Oil quantity & 24900 & $l$ \\
Un-tanking weight & 44400 & $\mathrm{Kg}$ \\
\hline
\end{tabular}

Bulletin of Electr Eng and Inf, Vol. 8, No. 3, September 2019 : 753 - 760 
The cross-section model of transformer is illustrated in Figure 1. The figure represents a model of 3 phase 30 MVA ONAN transformer consist of core type (3-limb three winding) with each phase of the winding wound on each of the limb one over the other. The transformer temperature distribution is being measured from $0 \mathrm{~cm}$ to $1045 \mathrm{~cm}$ as shown in Figure 1. Temperature settings for the $\mathrm{HV}$ windings and LV windings was set at $65^{\circ} \mathrm{C}$ while the ambient is sets at $30^{\circ} \mathrm{C}$. Corn oil was chosen to evaluate the thermal behaviour of vegetables oil cooling mechanism in a transformer.

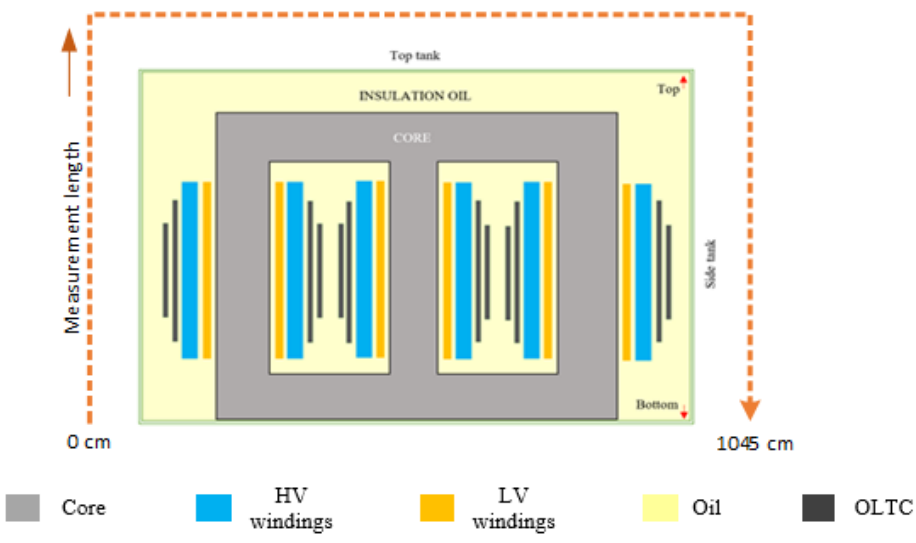

Figure 1. Transformer cross-sectional model

To compare the effects of HST, three locations of HSTs were added to the transformer winding to observe the temperature distribution effects. Table 2 tabulates the locations of the HSTs and the temperature of each fault along the HV winding. It is worth highlighting that all HSTs are simulated at the same time but at different locations.

Table 2. Hot spot value in the HV winding and their location

\begin{tabular}{ccc}
\hline Transformer conditions & Locations & Hot spot temperature $\left({ }^{\circ} \mathrm{C}\right)$ \\
\hline Hot spot 1 (HST 1) & Bottom & 100 \\
Hot spot 2 (HST 2) & Middle & 100 \\
Hot spot 3 (HST 3) & Top & 100 \\
\hline
\end{tabular}

\section{RESULTS AND ANALYSIS}

Figure 2 demonstrates the heat distribution result of a normal working 30 MVA transformer. It is evident that the transformer winding are the hottest part as they are the only heat source in the transformer [21]. Both low voltage (LV) and high voltage (HV) windings produced enough heat which contributed to the heat accumulation at the top of transformer tank. This proves the convection theory that the hot oil rises upward due to its smaller density and the cool oil sinks towards the bottom of the transformer which leads to the increment of the oil temperature along the axial direction [22].

Figure 3 shows the 30 MVA transformer outer surface temperature distribution using corn oil. It is observed from Figure 3 that the highest temperature is being accumulated at the top middle of the transformer. As studied by [23], the temperature pattern is downward due to the heat being accumulated in the middle of the tank. This can be proved with the simulation result where the maximum reading of $58.28^{\circ} \mathrm{C}$ is distributed at the middle of the tank. The curve shows the minimum temperature value of $56.21^{\circ} \mathrm{C}$ for the oil at the foremost left and right of the top middle section. According to [24, 25], the corn oil able to reduce the total heat build-up in the transformer. By looking at the simulation results, as in natural convection theory, the heated oil becomes less dense and goes upward and the cooler oil sinks towards the bottom of the tank as the movement of oil circulating inside the transformer [2]. It is believed the reason why the peak temperature is located at the middle in Figure 3 is due to the heat being accumulated at the centre and not at the side of the transformer which agreed by [12]. 

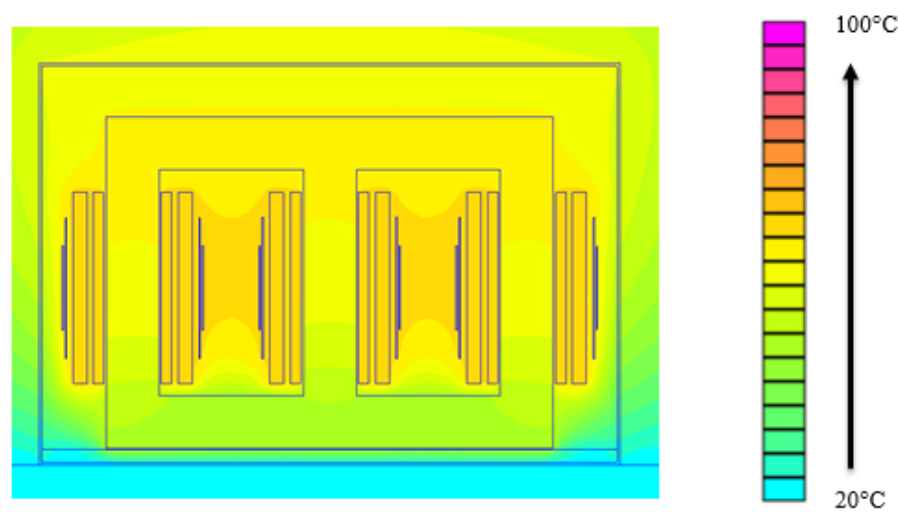

Figure 2. 30MVA corn oil insulated transformer heat distribution without HST

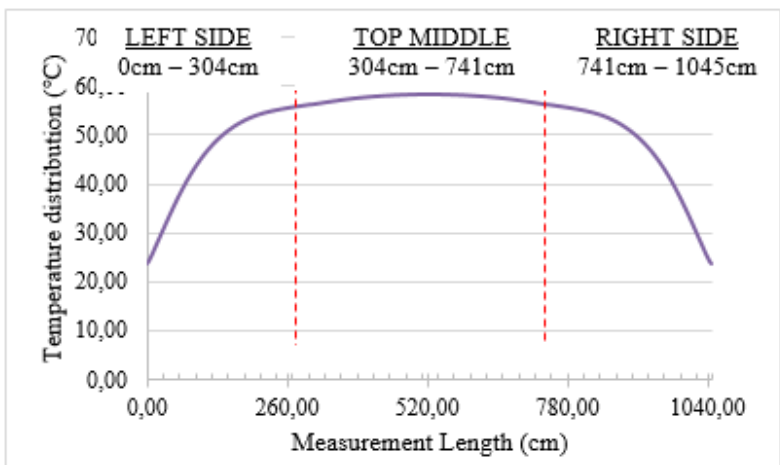

Figure 3. 30 MVA top oil temperature distribution using corn oil measured from $0 \mathrm{~cm}$ to $1045 \mathrm{~cm}$ at the outer surface of the transformer

\subsection{Heat distribution for ONAN transformer with the presence of hot spot temperature}

In order to characterize the thermal performance of the transformer in full capacity, the simulation is performed with of 3 faults/ hot spot temperature (HST) within the HV winding. It is important to observe the effect of HSTs based on the location and their temperature levels. The temperature rise due to the fault occurrence along the winding in mainly due to DC heat losses in the copper windings [4], which is significant in contributing to the total heat generated in the transformer. Figure 4 illustrates the working transformer with the HST present in the HV winding. The temperature distribution gives a clear observation that the presence of hot spot totally changes the temperature reading on the top part of transformer oil. Figure 5 shows transformer heat distribution with the present of hot spot at the bottom, the middle and the top of transformer winding. The comparison of top oil temperature distribution between normal condition and HST 1 until HST 3 is illustrated in Figure 6.

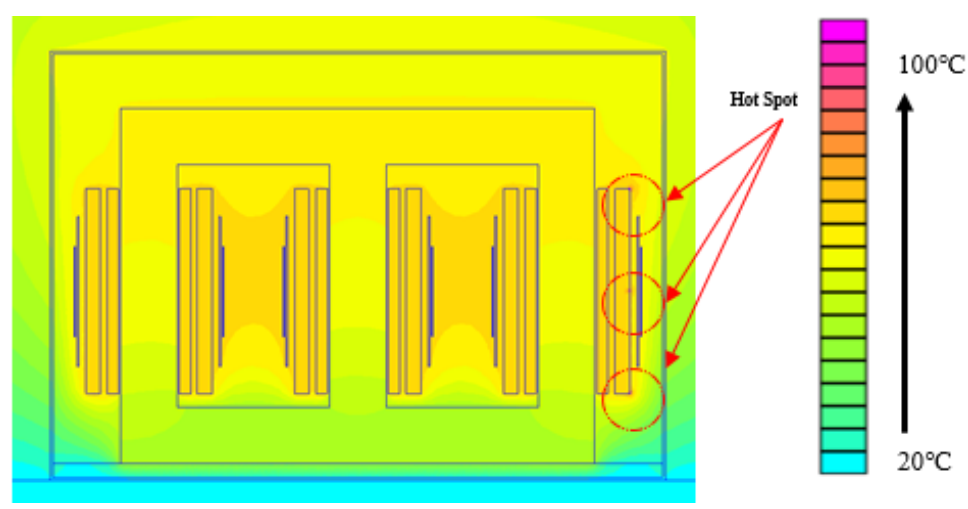

Figure 4. 30MVA corn oil filled transformer with the present of hot spot temperature 


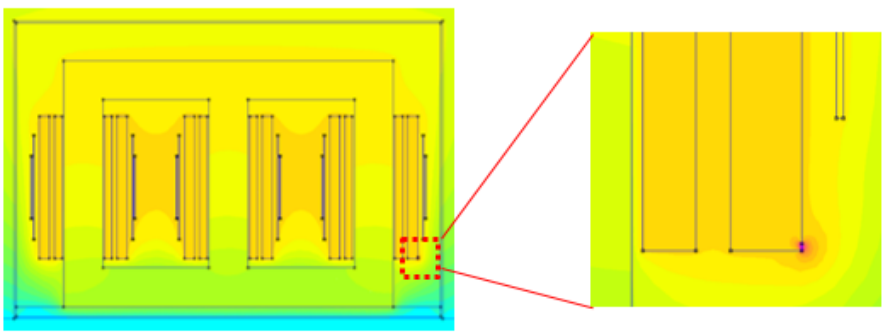

(a)

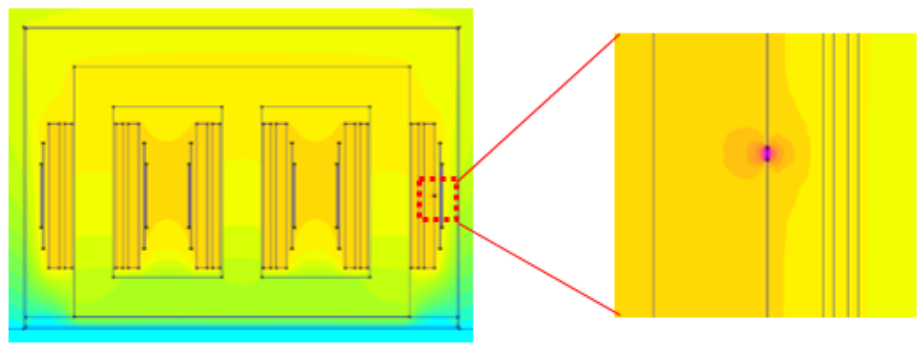

(b)

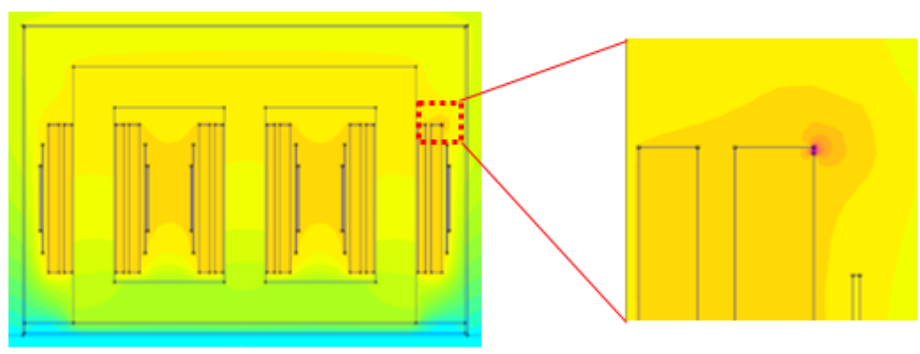

(c)

Figure 5. Transformer heat distribution with the present of hot spot at (a) the bottom, (b) the middle and (c) the top of transformer winding

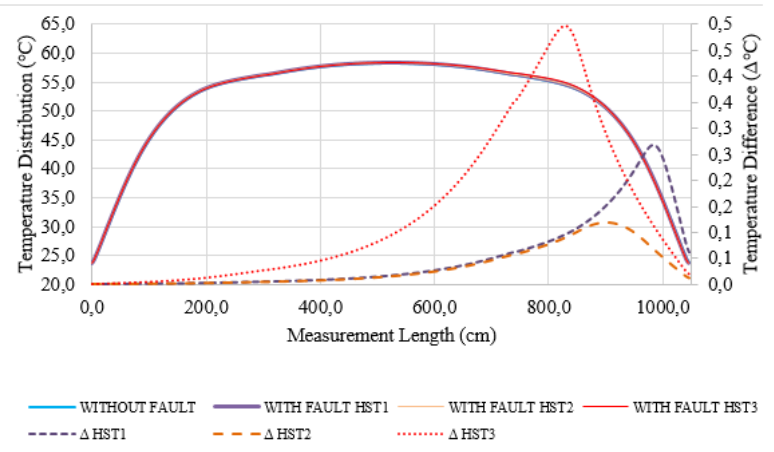

Figure 6. Comparison of top oil temperature distribution between normal condition (without fault) and with fault at HST1, HST2, and HST3

As can be seen from Figure 6, the placement of HST affects the total heat accumulated in the middle of the top of transformer tank. From the distribution, it can be considered as no major effect on top oil temperature when HST is located at the bottom of the HV winding compared to when HST is placed at the top of the winding [23]. The temperature plot indicates that HST located at the upper section of the winding

Top oil heat distribution pattern of ONAN corn oil based transformer with presence of... (M. A. Husin) 
provides heat distribution profile that increases towards the temperature of the upper section of the transformer. It has also been shown that the estimation of HST location may differ from the actual location in the transformer [5]. This study also proved that in the presence of HST in the winding, there is an increasing temperature on the overall heat distribution of the transformer [23].

\section{CONCLUSION}

Upon completion of this project, the desired thermal properties successfully illustrated the thermal behaviour of a 30 MVA ONAN transformer. The insulating oil used in this study are corn oil. It is obvious using corn oil in a transformer reduces the total heat build-up in the transformer compared with previous paper study on mineral oil. It is worth mentioning that the presence of hot spot temperature (HST) across HV winding contributes to the increment of heat in top oil of the transformer. The result reveals the location of HST at the bottom of the HV winding has little effect to the top oil temperature compared to when HST is at the top of the winding. From the temperature density plot, it can be concluded that the temperature is accumulated at the centre of the tank due to the natural convection of the oil. The study also shows that finding the hottest spot in the transformer is crucial to estimate the condition of transformer's oil degradation rates or its lifetime in addition to others heat-induced problems inside a transformer.

\section{ACKNOWLEDGEMENTS}

The authors express their sincere gratitude to Research Management Centre (RMC), Unversiti Tun Hussein Onn Malaysia (UTHM) for the use of facilities and for awarding research university grant under votes U863 and U948 from Ministry of Education Malaysia (Higher Education).

\section{REFERENCES}

[1] Seymour J, Horsley T. "The seven types of power problems”. APC, USA. 2005.

[2] Kulkarni SV, Khaparde S. "Transformer engineering: design and practice: Crc Press; 2004.

[3] Wen Q, Baohui Z, Zhiguo H, Zhiqian B. "Simulation and analysis of oil-immersed transformer based on thermalfluid coupled field". 2014 International Conference on Power System Technology. p. 826-31. 2014.

[4] Gour P, Chautre K, Kotwalla A, Arora T. "Effective Conversion of Transformer Losses into Dissipated Heat". International Journal of Engineering and Innovative Technology (IJEIT). 2012; 2:14-6.

[5] Dao T, Phung BT. "A study of hot-spot localization in distribution transformers". 2017 1st International Conference on Electrical Materials and Power Equipment (ICEMPE), 2017. p. 36-40.

[6] Van Sant MA. "Method of estimating solenoid heat accumulation and compensating for solenoid force loss". Google Patents; 2004.

[7] Colmenar-Santos A, Reino-Rio C, Borge-Diez D, Collado-Fernández E. "Distributed generation: A review of factors that can contribute most to achieve a scenario of DG units embedded in the new distribution networks". Renewable and Sustainable Energy Reviews. 2016; 59: 1130-48.

[8] Campos ART, Mariscal IC, Hernandez SG. "Simulation of a distribution transformer". WSEAS Transactions on Fluid Mechanics. 2012; 7: 106-15.

[9] Daghrah M, Wang ZD, Liu Q, Walker D, Krause C, Wilson G. "Experimental investigation of hot spot factor for assessing hot spot temperature in transformers". 2016 International Conference on Condition Monitoring and Diagnosis (CMD), 2016. p. 948-51.

[10] M. T. Isha and Z. Wang, "Transformer hotspot temperature calculation using IEEE loading guide," 2008 International Conference on Condition Monitoring and Diagnosis, Beijing, 2008, pp. 1017-1020.

[11] Z. Radakovic and K. Feser, "A new method for the calculation of the hot-spot temperature in power transformers with ONAN cooling," in IEEE Transactions on Power Delivery, vol. 18, no. 4, pp. 1284-1292, Oct. 2003.

[12] S. Mahmud, G. Chen, I. O. Golosnoy, G. Wilson and P. Jarman, "Experimental studies of influence of DC and AC electric fields on bridging in contaminated transformer oil," in IEEE Transactions on Dielectrics and Electrical Insulation, vol. 22, no. 1, pp. 152-160, Feb. 2015.

[13] T. O. Rouse, "Mineral insulating oil in transformers," in IEEE Electrical Insulation Magazine, vol. 14, no. 3, pp. 6-16, May-June 1998.

[14] M. A. G. Martins, "Vegetable oils, an alternative to mineral oil for power transformers- experimental study of paper aging in vegetable oil versus mineral oil," in IEEE Electrical Insulation Magazine, vol. 26, no. 6, pp. 7-13, November-December 2010.

[15] Bashi S, Abdullahi U, Yunus R, Nordin A. "Use of natural vegetable oils as alternative dielectric transformer coolants". Journal-The Institution of Engineers, Malaysia. 2006; 67: 4-9.

[16] Quinchia L, Delgado M, Reddyhoff T, Gallegos C, Spikes H. "Tribological studies of potential vegetable oil-based lubricants containing environmentally friendly viscosity modifier"s". Tribology International. 2014; 69:110-117.

[17] L. Marti, A. Rezaei-Zare and A. Narang, "Simulation of Transformer Hotspot Heating due to Geomagnetically Induced Currents," in IEEE Transactions on Power Delivery, vol. 28, no. 1, pp. 320-327, Jan. 2013. 
[18] Taheri S, Gholami A, Fofana I, Taheri H. "Modeling and simulation of transformer loading capability and hot spot temperature under harmonic conditions". Electric Power Systems Research. 2012; 86:68-75.

[19] Tsili MA, Amoiralis EI, Kladas AG, Souflaris AT. "Power transformer thermal analysis by using an advanced coupled 3D heat transfer and fluid flow FEM model". International Journal of Thermal Sciences. 2012; 53: 188-201.

[20] Faiz J, Sharifian M, Fakhri A. "Two-dimensional finite element thermal modeling of an oil-immersed transformer". European Transactions on Electrical Power. 2008; 18:577-94.

[21] Janura R, Gutten M, Korenciak D, Sebok M. "Thermal processes in materials of oil transformers". 2016 Diagnostic of Electrical Machines and Insulating Systems in Electrical Engineering (DEMISEE). 2016. p. 81-4.

[22] Reymond O, Murray DB, O'Donovan TS. "Natural convection heat transfer from two horizontal cylinders". Experimental Thermal and Fluid Science. 2008; 32:1702-9.

[23] N. A. Muhamad, H. Kamarden and N. A. Othman, "Heat distribution pattern of oil-filled transformer at different hottest spot temperature locations," 2015 IEEE 11th International Conference on the Properties and Applications of Dielectric Materials (ICPADM), Sydney, NSW, 2015, pp. 979-982.

[24] Taslak E, Kocatepe C, Arıkan O, Kumru C. "Electrical analysis of corn oil as an alternative to mineral oil in power transformers. World Academy of Science", Engineering and Technology International Journal of Electrical, Computer, Energetic, Electronic and Communication Engineering. 2015; 9:833-7.

[25] Kumar SS, Iruthayarajan MW, Bakrutheen M. "Investigations on the suitability of rice bran oil and corn oil as alternative insulating liquids for transformers". IEEJ Transactions on Electrical and Electronic Engineering. 2016; $11: 10-4$.

\section{BIOGRAPHIES OF AUTHORS}
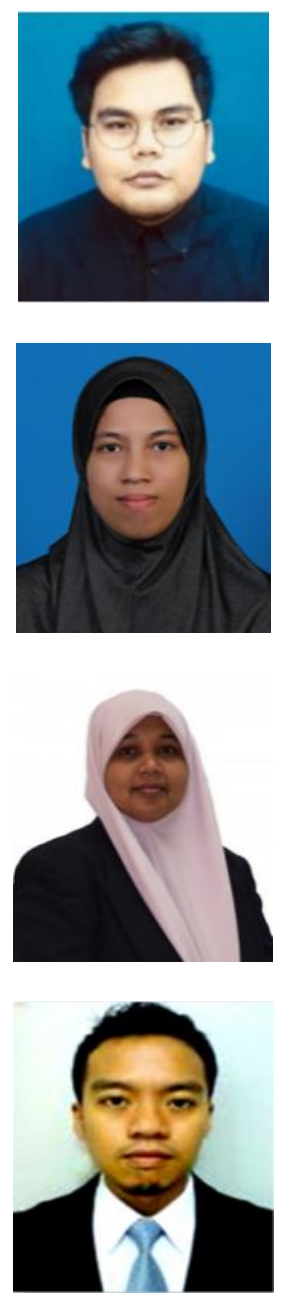

Muhammad Azizi Husin was born in Selangor, Malaysia on March 29, 1992. His passion in electrical engineering started in 2008 when he entered Sekolah Menengah Teknik Jengka (TEJA) and continued his further studies in Politeknik Sultan Azlan Shah (2010). He received his bachelor degree in Electrical engineering at Universiti Tun Hussein Onn Malaysia (UTHM), Malaysia in 2018. His research interest is more focus in transformer heat distribution.

Nordiana Azlin Othman was born in Johor, Malaysia on January 19, 1986. She is currently a Lecturer at the Department of Electrical Power Engineering, Universiti Tun Hussein Onn Malaysia. She received B. Eng. in Electrical Engineering from Universiti Teknologi Malaysia (UTM) in 2010 and PhD in High Voltage Engineering from UTM in 2016. Her research interest includes the detection and diagnostics of partial discharge and space charge in insulation for condition monitoring.

Nor Asiah Muhamad is currently a Senior Lecturer at the School of Electrical and Electronic Engineering, Universiti Sains Malaysia. She obtained her Ph.D. degree in 2009 from the University of New South Wales, Australia. She received her Bachelor's degree in Electrical and Electronic Engineering from Universiti Teknologi Petronas, Malaysia, in 2002 and Master's degree in Electrical Power Engineering from the University of South Australia in 2006. Her research interest is centred on power system equipment monitoring, in insulation diagnosis and the development of new systems for condition monitoring.

Hanafiah Kamarden@ Kamarudin was born in Johor, Malaysia in 1986. He received B.Eng. (Electrical- Control and Instrumentation) from Universiti Teknologi Malaysia (UTM) in 2012. He is currently pursuing his M.Eng. Degree at Institute of High Voltage and High Current (IVAT), Faculty of Engineering, UTM. His research interest includes the detection and monitoring of transformer overloads for condition monitoring. 


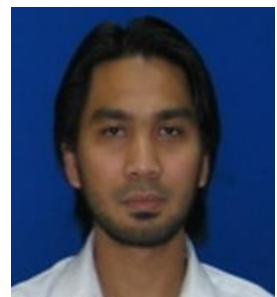

M. S. Kamarudin obtained his B. Eng. and M. Eng. Degrees in Electrical Engineering (Power) from Universiti Teknologi Malaysia (UTM) in 2003 and 2005, respectively, and a Ph.D. in High Voltage Engineering from Cardiff University, UK, in 2014. Currently, he is a senior lecturer in the Faculty of Electrical \& Electronic Engineering at Universiti Tun Hussein Onn Malaysia (UTHM). His research interests include gas discharges, high voltage surge arresters, and dielectrics and electrical insulation system. He is registered with the Board of Engineers Malaysia (BEM). He is also currently a member of IEEE and a graduate member of Institution of Engineers, Malaysia (IEM). 